\title{
Isolation of a cDNA encoding the largest subunit of TFIIA reveals functions important for activated transcription
}

\author{
Dongmin Ma, ${ }_{1}^{1}$ Hajime Watanabe, ${ }^{2}$ Fred Mermelstein, ${ }^{1}$ Arie Admon, ${ }^{3}$ Kiyoshi Oguri, ${ }^{2}$ \\ Xiaoqing Sun, ${ }^{1}$ Tadashi Wada, ${ }^{2}$ Takeshi Imai, ${ }^{2}$ Toshifumi Shiroya, ${ }^{2}$ Danny Reinberg, ${ }^{1,4}$ \\ and Hiroshi Handa ${ }^{2}$

\begin{abstract}
'Department of Biochemistry, Robert Wood Johnson Medical School, University of Medicine and Dentistry of New Jersey, Piscataway, New Jersey 08854-5635 USA; ${ }^{2}$ Faculty of Bioscience and Biotechnology, Tokyo Institute of Technology, Midoriku, Yokohama 227, Japan; ${ }^{3}$ Howard Hughes Medical Institute, Department of Molecular and Cell Biology, University
\end{abstract} \\ of California, Berkeley, California 94728 USA
}

Transcription factor IIA has been shown to interact with the TATA-binding protein and to act early during preinitiation complex formation. The human factor is composed of three subunits $(\alpha, \beta, \gamma)$. A human cDNA clone encoding the largest subunit of TFIIA $(\alpha)$ was isolated. The recombinant $\alpha$ polypeptide, together with the $\beta$ and $\gamma$ subunits, was capable of reconstituting TFIIA activity. Studies using antibodies raised against recombinant $\alpha$ polypeptide demonstrate that TFIIA can be an integral component of the preinitiation complex. We demonstrate that TFIIA not only interacts with TBP but also can associate with the TFIID complex. Functional assays establish that TFIIA has no apparent role in basal transcription but plays an important role in activation of transcription. Interestingly, amino acid sequence analyses of the $\beta$-subunit demonstrate these residues to be entirely contained within the carboxyl terminus of the cDNA clone encoding the $\alpha$-subunit.

[Key Words: TFIIA; TATA-binding protein; preinitiation complex; antirepression; transcriptional activation]

Received August 27, 1993; revised version accepted September 24, 1993.

An enormous effort has been devoted in recent years toward the characterization of the factors that are necessary, in addition to RNA polymerase II (RNAPII), to initiate transcription from class-II promoters. This has resulted in the identification of seven activities that are required for basal transcription: TFIIA, TFIIB, TFIID, TFIIE, TFIF, TFIIH, and TFII (Zawel and Reinberg 1993). The polypeptide composition of most of the general transcription factors (GTFs) has been defined, and many of the corresponding cDNAs have been isolated. These factors mediate transcription initiation by forming a multiprotein complex with RNAPII on the promoter. TFIID, the only GTF that contains a sequencespecific DNA-binding activity, initiates complex assembly by binding to the TATA box. TFIIA interacts with the TATA-binding protein (TBP) component of TFIID and stabilizes the TFIID-DNA protein complex (for details, see Zawel and Reinberg 1992). TFIIA has the ability to associate with TBP at any step during preinitiation complex formation (Flores et al. 1992).

The TBP activity is contained in a $38-\mathrm{kD}$ polypeptide (Hoffman et al. 1990; Kao et al. 1990; Peterson et al. 1990). However, native preparations of TFIID have a much larger apparent molecular weight (Zhou et al.

${ }^{4}$ Corresponding author.
1992), suggesting that in vivo TBP exists in a multisubunit protein complex (Lewin 1990). Both TFIID and TBP are equally capable of mediating basal transcription. However, while TFIID can support activated transcription by sequence-specific regulatory factors, TBP cannot. The studies of Dynlacht et al. (1991) demonstrated that at least six polypeptides are tightly associated with Drosophila TBP in vivo and that some of these TBP. associated factors (TAFs) can function as coactivators. Progress in this area has resulted in the isolation of cDNA clones encoding TAF250 (Hisatake et al. 1993; Kokubo et al. 1993; Ruppert et al. 1993; Weinzierl et al. 1993), -110 (Hoey et al. 1993), -80 (Dynlacht et al. 1993), and - 40 (Goodrich et al. 1993). These studies have unequivocally established that TAFs are required for activation and that coactivator interactions are highly specific (Tanese et al. 1991).

TBP is only a $38-\mathrm{kD}$ polypeptide, yet already we know of more intermolecular interactions involving TBP than are physically possible for a protein of that size. These include interactions with some of the TAFs, activators such as VP16, Zta, and Ela (Stringer et al. 1990; Horikoshi et al. 1991; Ingles et al. 1991; Lee et al. 1991; Liberman and Berk 1991; Zhou et al. 1992), repressors of basal transcription such as $\mathrm{Dr}_{1}$ (Inostroza et al. 1992) and $\mathrm{Dr}_{2}$ (Merino et al. 1993), as well as with other GTFs such as 
TFIIB (Ha et al. 1993), TFIIA (Usuda et al. 1991; Cortes et al. 1992; Coulombe et al. 1992; also see below), and RNAPII (Usheva et al. 1992; for review, see Drapkin et al. 1993|. Furthermore, TBP has been shown to be an integral component of a protein complex implicated in RNAPI and RNPIII transcription (for review, see Hernandez 1993).

Significant progress has been made in our understanding of the role and requirement of TFIIA in transcription. In the past, variable requirements for TFIIA in reconstituted transcription systems were reported. Reinberg et al. \{1987) found that TFIIA was required when purified, but not crude preparations of TFIID were used. Cortes et al. (1992) determined that crude preparations of TFIIA consisted of two distinguishable activities: TFIIA, which was purified to homogeneity, and TFIIJ. In agreement with earlier observations demonstrating a requirement for the TFIIA protein fraction (containing TFIIJ) in transcription, TFIIJ was found to be essential for transcription only when highly purified TFIID or recombinant TBP was used. Crude TFIID preparations obviate the TFII) requirement because of contaminating TFIIJ (Flores et al. 1992). Interestingly, TFIIA could stimulate basal transcription when native TFIID was utilized but was without effect when TBP was used. Cortes et al. (1992) postulated that TFIIA may function to remove, by way of its association with TBP, negative components that associate with TFIID. Support for this hypothesis was recently provided by Merino et al. (1993), who observed that the activity of $\mathrm{Dr}_{2}$, a repressor of basal transcription present in TFIID, is counteracted by TFIIA (for review, see Drapkin et al. 1993). Buratowski and Zhou (1992) have shown that the area of TBP mediating the interaction with TFIIA is within the highly conserved carboxy. terminal domain. Mutations to the conserved basic region separating the direct repeats in yeast TBP abolish its ability to interact with human TFIIA. TFIIA was recently cloned from yeast and found to be capable of replacing human TFIIA in a reconstituted system (Ranish and Hahn 1992; Ranish et al. 1992).

Here, we report the isolation of a cDNA encoding the largest subunit of human TFIIA. Our studies demonstrate that TFIIA is associated with the TFIID complex. Our findings indicate that TFIIA has no role in basal transcription but is necessary for activation.

\section{Results \\ Molecular cloning of the largest subunit ( $\alpha$ ) of TFIIA}

The ability of TFIIA to stimulate the binding of TBP to the TATA motif (Buratowski et al. 1989; Maldonado et al. 1990; Lee et al. 1992) was used as an assay to purify TFIIA (Usuda et al. 1991; Cortes et al. 1992). This procedure resulted in a protein preparation containing three predominant polypeptides with $R_{\mathrm{f}}$ values of $\sim 37(\alpha), 19$ $(\beta)$, and $13(\gamma) \mathrm{kD}$ (Cortes et al. 1992; also see Fig. 2A). The polypeptide composition of this protein preparation is in perfect agreement with previous studies that recon- stituted TFIIA activity from renatured polypeptides (Cortes et al. 1992). The 37-, 19-, and 13-kD polypeptides in the TFIIA protein fraction were transferred to PVDF membrane and digested with different proteases as described in Materials and methods. Peptides were recovered and sequenced. Lysyl-endopeptidase treatment of the $37-\mathrm{kD}$ subunit generated three peptides, the sequences of which are shown in Figure 1A (peptides e-g). A degenerate oligonucleotide was synthesized on the basis of the amino acid sequence from peptide $g$ (see Fig. 1A) and used to screen a HeLa cellular cDNA library. Eight positive cDNA clones were isolated from $3 \times 10^{5}$ independent clones. The complete nucleotide sequence of the longer cDNA clone isolated (TFIIA- $\alpha$ ) is shown in Figure 1A. The nucleotide sequence of the cDNA predicts a long open reading frame encoding a polypeptide of 376 amino acids, with a calculated $M_{\mathrm{r}}$ of 41,511 and an isoelectric point of 4.25 . The sequence of the longest cDNA clone contained all of the peptide sequences derived from the $37-\mathrm{kD}$ polypeptide (Fig. 1). A second cDNA clone (TFIIA- $\alpha^{*}$ ), whose open reading frame started at residue 40, was also isolated (Fig. 1A).

Computer search of the SWISSPROT data base failed to detect any genes with extensive sequence similarity to the cDNAs. cDNA clones encoding the yeast Saccharomyces cerevisae TFIIA have been isolated (Ranish et al. 1992). Amino acid sequence comparison between the cDNA clone encoding the yeast TFIIA large subunit and the longer human TFIIA cDNA clone revealed low homology ( $21 \%$ identity, $45 \%$ similarity). Amino acid conservation between these cDNA clones was most evident when the amino- and carboxy-terminal residues were analyzed (Fig. 1B).

The polypeptide encoded by the longer cDNA clone was found to contain three glutamine-rich regions among positions 69-104, 173-204, and 247-272, with glutamine contents of $44 \%, 41 \%$, and $39 \%$, respectively. Interestingly, there are seven consecutive histidine residues within the glutamine residues. Tracts of histidine residues have also been observed in other transcription factors such as YY1 (Hariharan et al. 1991; Park and Anchison 1991; Shi et al. 1991; Flanagan 1992), homeotic proteins (LaRosa and Gudas 1988), and POU-related proteins (Monuki et al. 1990; He et al. 1991). The function of this motif is presently not known. Of potential interest are two acidic regions between positions $282-300$ and $310-332$, in which the content of acidic residues is $89 \%$ and $52 \%$, respectively. It is noteworthy that the larger subunit of yeast TFIIA also contains two acidic regions (Ranish et al. 1992). It has been shown that lysine residues in the basic region of TBP are involved in the interaction with TFIIA (Buratowski and Zhou 1992; Lee et al. 1992). It is thus possible that the acidic regions in TFIIA may mediate the interaction with TBP. On the other hand, glutamine- or acid-rich residues have been proposed to constitute activation domains. We have found that the TFIIA- $\alpha-c D N A$ clone can activate transcription of reporter genes bearing LexA DNA recognition elements in yeast when fused to a LexA DNA-binding domain (data not shown). 
Ma et al.

Figure 1. Nucleotide sequence of a cDNA encoding the largest subunit of TFIIA. $(A)$ Nucleotide and amino acid sequence /singleletter code) of the largest cDNA clone isolated. The coding sequence of TFIIA- $\alpha$ starts at nucleotide 140. The start codon of TFIIA- $\alpha^{*}$ starts at nucleotide 259 , which corresponds to the codon encoding amino acid residue 40 of TFIIA- $\alpha$ (indicated by an arrow). The $5^{\prime}$-untranslated sequence of the cDNA encoding $\alpha^{*}$ is $5^{\prime}$-ACCACGTGATCACGCGAGCGTTGGAGAGGC-3' and continues with nucleotide residue 172 of TFIIA- $\alpha$. The underlined nucleotides denote a translational stop codon. The underlined amino acids indicate the different peptide sequences obtained. Lowercase letters $a-d$ and $e-g$ denote peptides isolated after cleavage with LysC - and lysyl-endopeptidases, respectively. Numbers 1-3, at the carboxyl terminus of the cDNA, denote peptides obtained after LysC-endopeptidase cleavage of the $19-\mathrm{kD}$ subunit of TFIIA. $|B|$ Amino acid sequence comparison at the amino and carboxyl termini of the human and yeast TFIIA largest subunit. Vertical lines and asterisks indicate identities and similarities, respectively.

$\mathbf{A}$

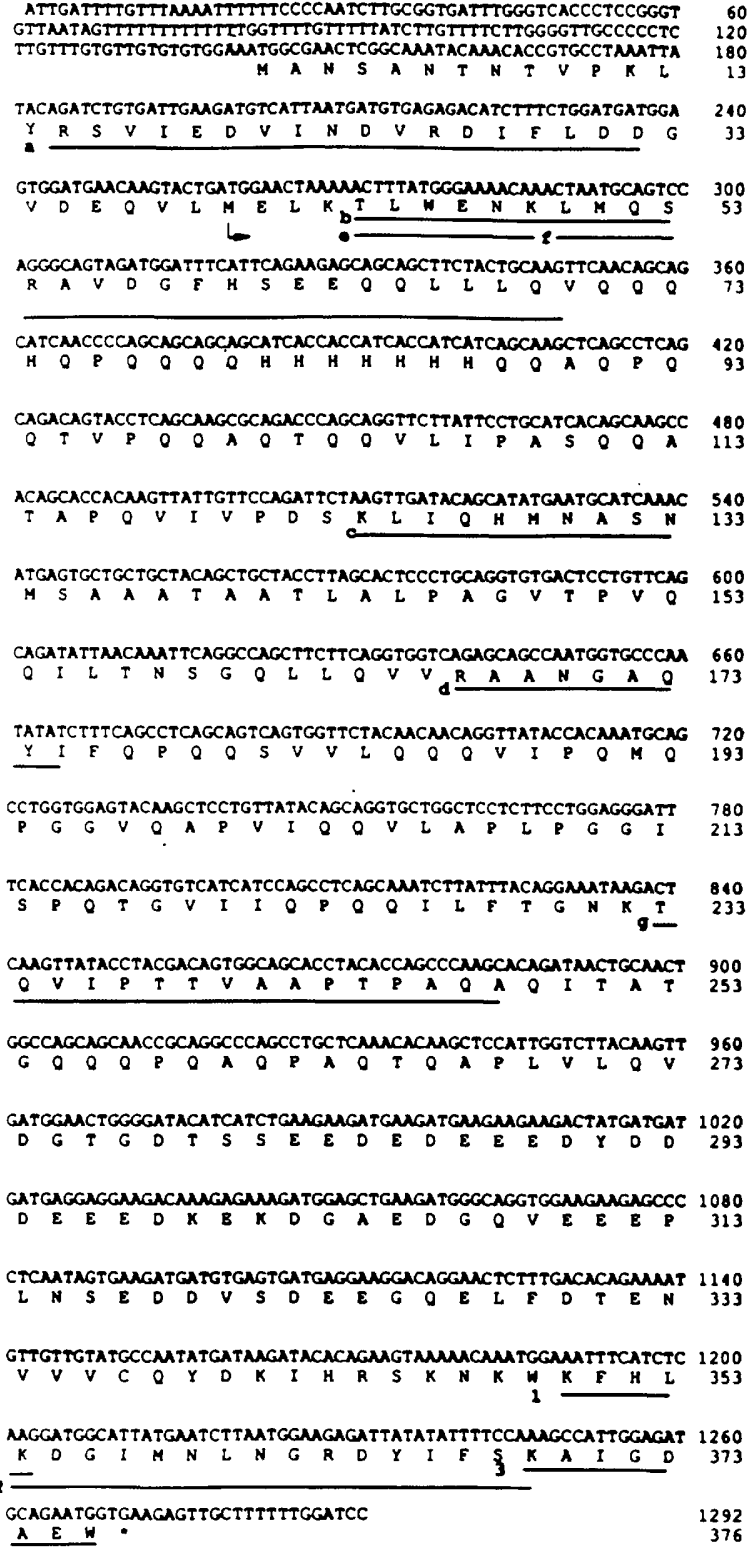

B

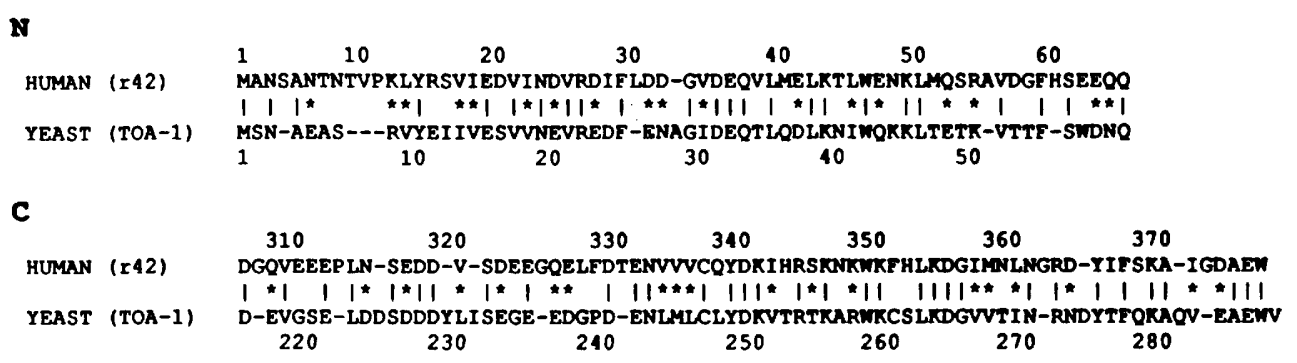

The polypeptide encoded by the longest $c D N A$ clone is a component of TFIIA

To analyze whether the isolated cDNA encoded TFIIA- $\alpha$, the recombinant protein was purified and used to generate antibodies. Because the cDNA clone uncovered the presence of seven consecutive histidine residues in the protein, we analyzed whether TFIIA activity could be retained on a nickel column. The result of this analysis is shown in Figure 2. TFIIA activity was retained on a nickel column (Fig. 2B), and the $37-\mathrm{kD}$ polypeptide could be immunologically detected in the bound fraction (Fig. 


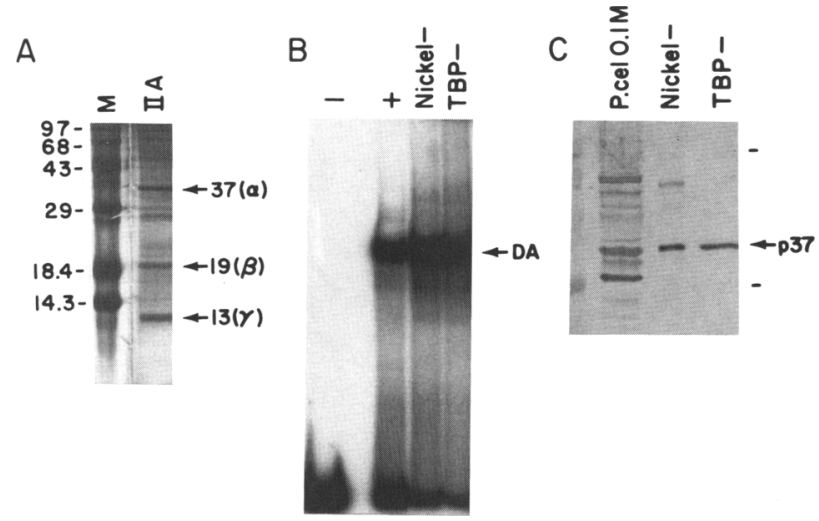

Figure 2. Purification of TFIIA by nickel and TBP affinity chromatography. $(A)$ Silver staining of the polypeptides copurifying with TFIIA after purification by chromatography of HeLa cell nuclear extracts on phosphocellulose, nickel, and TBP affinity chromatography. The arrows indicate the subunits of TFIIA. Molecular mass markers are indicated at left. $(B)$ A DNA-binding assay assessing the ability of TFIIA to stimulate the formation of the DA complex using the gel mobility shift assay. (Nickel and TBP) The TFIIA protein pools analyzed $\{4$ and $1 \mu l$, respectively|. Negative $(-)$ and positive $|+|$ symbols denote reactions incubated with a 5 '-end labeled DNA fragment containing the Ad-MLP-TATA motif and yeast TBP in the absence and presence (DEAE-5PW protein pool) of TFIIA, respectively. $(C)$ Antibodies raised against the recombinant TFIIA- $\alpha$ react, in Western blot, with a polypeptide of $\sim 37 \mathrm{kD}$. The different TFIIA protein fractions used are indicated at the top. The lanes on the left side denote the 29 - and $68-\mathrm{kD}$ markers.

2C). Our previous studies have demonstrated that TFIIA interacts directly with TBP and that TBP affinity chromatography results in extensive purification of TFIIA (Usuda et al. 1991; Cortes et al. 1992; Coulombe et al. 1992). Thus, the nickel column protein pool was purified further using a TBP affinity column. Silver staining of the polypeptides in the TFIIA protein fraction obtained by sequential chromatography on phosphocellulose, followed by affinity chromatography on nickel and TBP affinity columns, is shown in Figure 2A. Both TFIIA activity (Fig. $2 \mathrm{~B}$ ) and the $37-\mathrm{kD}$ polypeptide (Fig. $2 \mathrm{C}$ ) were retained by the column. These results demonstrate that antibodies generated with recombinant protein cross-react with the $37-\mathrm{kD}$ polypeptide present in the TFIIA protein fraction.

\section{TFIIA and the preinitiation complex}

The studies presented above indicate that antibodies raised against the recombinant protein reacted with a polypeptide determined previously to be a component of TFIIA. To further scrutinize the specificity of the antibodies to a subunit of TFIIA, their effect on different preinitiation complex intermediates was analyzed. Previous studies have demonstrated that TFIIA is dispens. able for basal transcription and is consequently not essential for the formation of a transcription competent complex. However, because TFIIA interacts with TBP,
TFIIA can associate with different preinitiation complex intermediates (Cortes et al. 1992; Flores et al. 1992).

The formation of a transcription-competent complex is a highly ordered process featuring numerous distinct preinitiation complex intermediates that can be resolved using the gel mobility shift assay (Buratowski et al. 1989; Flores et al. 1992). An early intermediate is the association of TBP with the TATA motif. The TBP-DNA protein complex is recognized by TFIIA and/or TFIIB generating the DA, DB, and DAB complexes (see Fig. 3A). The addition of antibodies raised against the recombinant TFIIA- $\alpha$ polypeptide resulted in a supershift of the $\mathrm{DA}$ and $\mathrm{DAB}$ complexes (lanes 2 and 4, respectively). The $\mathrm{DAB}$ complex provides the foundation for the entry of the RNAPII-IIF complex, resulting in the DABPolf complex (lane 5). This complex was also supershifted by the antibodies (lane 6). The observed supershift of the complexes by the antibodies was specifically attributable to the presence of TFIIA, as complexes formed in the absence of TFIIA (DB and DBPolF, see lane 7) were not affected by the antibodies (lane 8 ). These results, together with those presented in Figure 2, establish that the cDNA described above encodes a polypeptide that is contained in the TFIIA protein fraction.

To analyze whether the protein encoded by the longest cDNA could reconstitute TFIIA activity, recombinant protein was isolated from Escherichia coli and analyzed for its ability to interact with TBP in a gel mobility shift assay. No activity could be demonstrated with the recombinant polypeptides in the absence of the other TFIIA subunits (data not shown). However, when the recombinant $\alpha$ polypeptide was mixed with the other two components of TFIIA /isolated from a polyacrylamide-SDS gel followed by renaturation), a DA complex was demonstrated that comigrated on a native gel with the complex formed with native TFIIA (Fig. 3B, cf. lanes 4 and 1 , respectively). The 19 - and $13-\mathrm{kD}$ subunits of TFIIA, in the absence of recombinant $\alpha$, were unable to affect the mobility of the TBP-TATA complex (lane 5). The polypeptide encoded by the shorter $\operatorname{cDNA}\left(\alpha^{*}\right)$ was capable, but to a much lesser extent with respect to $\alpha$, of forming the DA complex (cf. lanes 3 and 4). Thus, the results of Figure 3 demonstrate that the longer cDNA encodes the largest subunit of TFIIA. Moreover, the result obtained with $\alpha^{*}$ indicates that the amino-terminal 39 amino acids of TFIIA- $\alpha$ are functionally important.

\section{TFIIA and transcription}

Having demonstrated that the longer cDNA clone encodes the $\alpha$-subunit of TFIIA, we analyzed the effect of the antibodies on transcription. In agreement with our previous observations demonstrating that TFIIA has no effect on transcription when reactions are reconstituted with highly purified factors and TBP (in lieu of TFIID), we were unable to demonstrate an effect of TFIIA (Fig. $4 \mathrm{~A}$, cf. lanes 1 and 2 ) or of the anti-TFIIA- $\alpha$ antibodies in basal transcription (lanes 3-5). However, when transcription reactions are reconstituted with TFIID (in lieu of TBP), TFIIA has a stimulatory effect (see below; Cortes 
Figure 3. The polypeptide encoded by the longest cDNA is the $\alpha$-subunit of TFIIA. $(A)$ The DA, DAB, and DABPolF intermediates and complexes in the absence of TFIIA (i.e., $\mathrm{DB}$ and DBPolF), were formed on the AdMLP-TATA motif as described in Materials and methods. Half of the various complex was incubated with anti-TFIIA- $\alpha$ antibodies, as indicated at the top. The complexes were separated on a native polyacrylamide gel. The migration of the different DNA-protein complexes is indicated at left. (SSC) Complexes that were supershifted due to the association of the antibodies. $(B)$ Recombinant $\alpha$ or $\alpha^{\star}$ polypeptide $(400 \mathrm{ng}$ each, isolated as described in Materials and methods) was mixed with 5 ng each of the $\beta$ - and $\gamma$-subunits of TFIIA (see Materials and methods), as indicated at the top. After denaturation and renaturation of the different mixtures, one-thirtieth was added to DNA-binding assays composed of a DNA fragment containing the

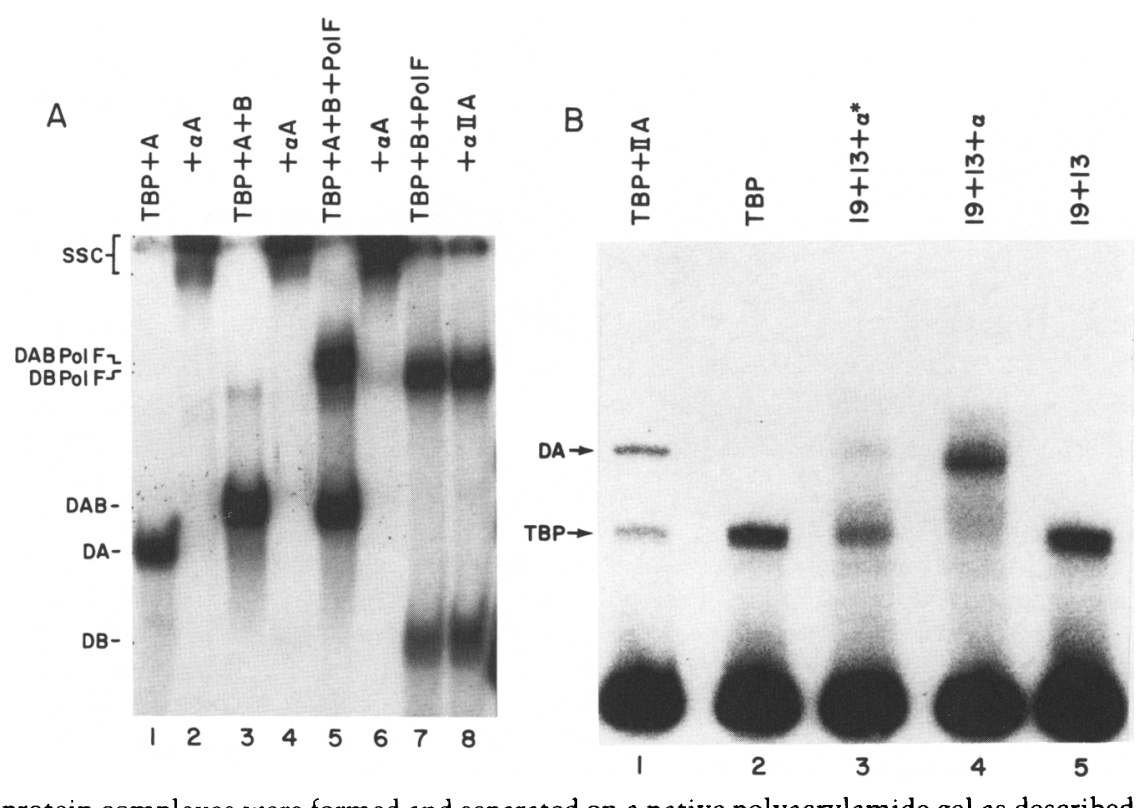
Ad-MLP-TATA motif and yeast TBP. DNA-protein complexes were formed and separated on a native polyacrylamide gel as described by Usuda et al. (1991). The control reaction (lane 1) contained TFIIA (5 ng), which was purified by TBP affinity chromatography, as described by Usuda et al. (1991). The migration of the different complexes is indicated at left.

et al. 1992). We reason that this stimulatory effect of TFIIA is attributable, in part, to the presence of negative factors in TFIID that are displaced from the complex upon interaction of TFIIA with the TBP component of TFIID. One such factor is $\mathrm{Dr}_{2}$ (Merino et al. 1993). We analyzed whether anti-TFIIA- $\alpha$ antibodies affected the ability of TFIIA to overcome $\mathrm{Dr}_{2}$-mediated repression of transcription. In reactions reconstituted with TBP, the addition of $\mathrm{Dr}_{2}$ resulted in repression of transcription (Fig. 4B, lanes 3-6). TFIIA could effectively overcome this repression (lanes 7-9), recapitulating the effect of TFIIA in transcription assays reconstituted with TFIID. The addition of anti-TFIIA- $\alpha$ antibodies suppressed the ability of TFIIA to overcome repression by $\mathrm{Dr}_{2}$ (lanes 10-13).

To investigate whether TFIIA has any role in activated transcription, reactions were performed with nuclear extracts supplemented with the activator Gal4-VPl6 and with DNA templates containing or lacking Gal4-binding sites (for details, see Materials and methods). The addition of Gal4-VP16 resulted in activation of transcription only from the template containing the Gal4 responsive elements (Fig. 4C, cf. lane 1 and 2). The addition of antiTFIIA- $\alpha$ antibodies resulted in inhibition of activated transcription (lanes 3-6). The inhibition was specific, as the addition of excess TFIIA could overcome this inhibition (lanes 7-9). Because transcription was directed by TFIID (in lieu of TBP), the template lacking Gal4 responsive elements was also stimulated by TFIIA /cf. lane 1 with lanes 7-9). Therefore, transcription from this template was no longer refractory to the TFIIA- $\alpha$ antibodies (lane 6). However, it is interesting to note that the antibodies have a much greater effect on activated transcription. These results are not activator specific, as different activators (Gal4-Pro) yielded similar results (data not shown|. The most logical interpretation of these observations is that TFIIA plays an important role in transcriptional activation. These results, however, do not rule out the possibility that TFIIA may influence activation in an indirect fashion. It is possible that TFIIA is necessary solely to remove repressors that have a dominant effect. Regardless of the precise mechanisms, our observations demonstrate that (1) TFIIA has no role in basal transcription, (2) TFIIA can overcome the action of repressors such as $\mathrm{Dr}_{2}$, and (3) TFIIA plays a role in the activation process. These results are in agreement with the observations of Hahn and colleagues demonstrating that TFIIA is essential for viability in yeast (Ranish et al. 1992).

\section{TFIIA associates with the TFIID complex}

Previous studies have demonstrated that TFIIA interacts with TBP. Moreover, the results presented above, implicating the involvement of TFIIA in activated transcription, suggest that TFIIA interacts with the TFIID complex. The nature of this interaction was analyzed by immunoprecipitation with anti-TFIIA- $\alpha$ antibodies, monoclonal antibodies (SL39-2-575) recognizing the species-specific amino terminus of human TBP (gift of Dr. N. Hernandez, Cold Spring Harbor Laboratory, NY), as well as TAF80 and TAF150 monoclonal antibodies shown to immunoprecipitate the TFIID complex (gift of Dr. R. Tiian, University of California, Berkeley). Immunoprecipitation of a polypeptide of $\sim 37 \mathrm{kD}$ from nuclear extracts with TBP monoclonal antibodies was detected in a Western blot with anti-TFIIA- $\alpha$ antibodies (Fig. 5A, lane 1). This polypeptide represents the largest subunit 

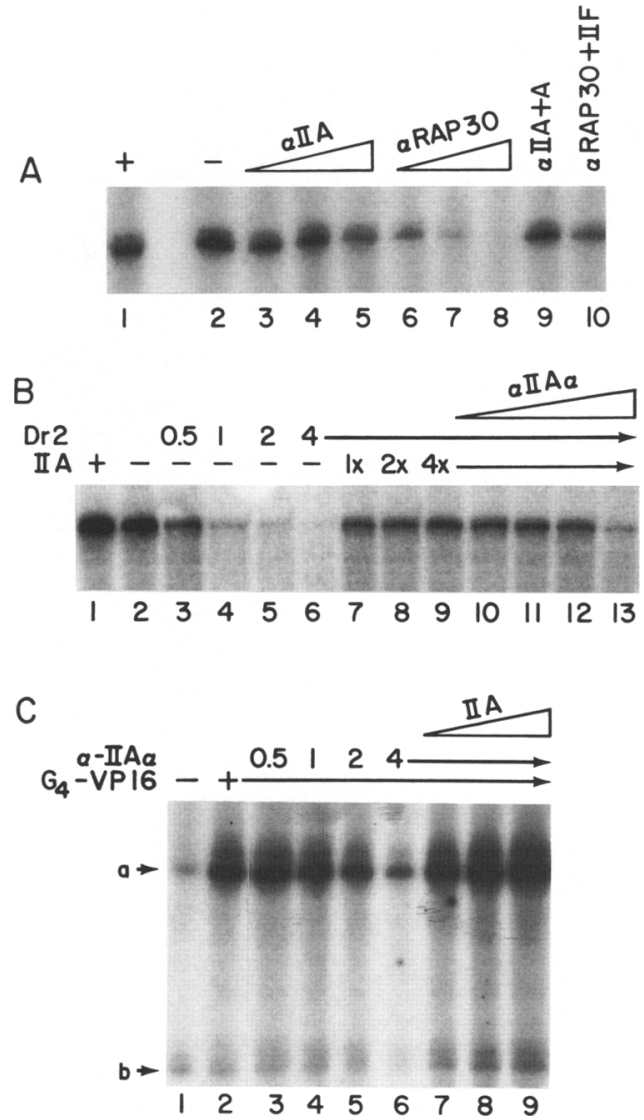

Figure 4. The effect of TFIIA in transcription. (A) Basal transcription. Reaction mixtures were reconstituted with TBP and GTFs as described in Materials an methods using the minimal sequences of the Ad-MLP promoter and directing transcription of a G-less cassette. Anti-TFIIA- $\alpha(0.5,1$, and $2 \mu 1)$ or anti$\operatorname{RAP} 30(0.5,1$, and $2 \mu \mathrm{l})$ antibodies were added as indicated at the top. The last two lanes indicate addition of excess amount of TFIIA or TFIIF to reactions containing the highest amount of antibodies. $(B)$ Antirepression. Reactions were reconstituted as described in $A$ with and without TFIIA $\mid 1 \mu l$, TBP affinity chromatography) as indicated at the top. Reactions were also supplemented with $\mathrm{rDr}_{2}$ and anti-TFIIA- $\alpha$ antibodies $(0.5,1,1.5$, and $2 \mu \mathrm{l})$, as indicated. $(C)$ Activated transcription. Transcription reactions were performed in nuclear extract and contained Gal4-VP16, as indicated. Two different DNA templates were added to the reaction, as described in the text and in Materials and methods. In addition, reactions also received anti-TFIIA- $\alpha$ antibodies and TFIIA (TBP affinity chromatography, 1, 2, and 3 $\mu l)$ as indicated at the top. Markers at left denote activated $(a)$ and basal (b) transcription.

of TFIIA as determined by immunoreactivity with antiTFIIA- $\alpha$ antibodies (Fig. 5A, lanes 2,4). Because the 37 . $\mathrm{kD}$ polypeptide could not be immunoprecipitated by the TBP monoclonal antibodies from a protein fraction devoid of TFIID (lane 3), but containing TFIIA (lane 4), we concluded the existence of an interaction between TFIID and TFIIA in vivo. However, the studies described above were performed with nuclear extracts and do not demonstrate a direct interaction between TFIIA and the TFIID complex. Therefore, a partially purified TFIID pro- tein fraction was incubated in the presence and absence of TFIIA and proteins immunoprecipitated with antiTFIIA antibodies followed by Western blot analysis using anti-TBP antibodies. The results in Figure 5B demonstrate that a polypeptide of $\sim 40 \mathrm{kD}$ is precipitated by both the SL39-2-575 monoclonal antibodies and by TFIIA antibodies (lanes 4 and 2, respectively). This polypeptide represents TBP because, in addition to being immunoprecipitated by the SL39-2-575 monoclonal antibodies, it comigrates with TBP on PAA-SDS gels /data not shown) and is absent in a crude TFIIA protein fraction (Fig. 5B, lane 3; see also Cortes et al. 1992) devoid of TBP (lane 3). The interaction between TFIIA and TFIID was analyzed further using immunoaffinity-purified TFIID and antibodies directed against TAF80 and TAF150. Purified TFIID complexes were incubated in the presence and absence of TFIIA and proteins immunoprecipitated with anti-TAF80 or anti-TAF 150 antibodies. The presence of TFIIA in the TFIID complex was detected by Western blot analysis using anti-TFIIA- $\alpha$ antibodies. Both TAF antibodies immunoprecipitated TFIIA (Fig. 5C, lanes 2,4). The extent of TFIIA varied with the TAF antibodies (Fig. $5 \mathrm{C}$ ) but correlated with the amount of TBP that was immunoprecipitated by the TAF antibodies (data not shown). Thus, the analyses presented above demonstrate an interaction between TFIIA with the TFIID complex.

The complexity of the gene encoding the $\alpha$-subunit of TFIIA

The molecular cloning of the TFIIA- $\alpha$ subunit resulted in the isolation of two different cDNA clones differing in their 5' sequences (Fig 1). These cDNAs have the capacity to produce two polypeptides-one that lacks the first 39 amino acids (Fig. 1). We were not able to detect the polypeptide encoded by the smaller cDNA clone (TFIIA$\alpha^{*}$ in our Western blot analysis; thus, its relevance in vivo is not clear. Northern blot analysis using poly $(\mathrm{A})^{+}$ RNA isolated from HeLa cells and various other tissues demonstrates a 7.0-kb RNA that hybridizes specifically with the cDNA encoding TFIIA- $\alpha$ (Fig. 6A). Variable levels of RNA complementary to TFIIA- $\alpha$ were observed among the tissues tested (Fig. 6A). The difference in the amounts of RNA was not attributable to the amount of poly $\mid A)^{+}$RNA on the blot, as similar levels of steadystate RNA complementary to actin was observed in most of the tissues analyzed, with the exception of skeletal muscle and liver (Fig. 6B). Moreover, variable amounts of RNA complementary to TFIIB were observed in the different tissues (Fig. 6C). Interestingly, steadystate levels of RNA complementary to TFIIB and TFIIA were not congruent in the tissues analyzed. This indicates that the expression of the general transcription factors (TFIIA and TFIIB) varies in different tissues. In interpreting these data, it is pertinent to underscore that TFIIA may not be a basal transcription factor but is involved in antirepression and transcriptional activation. Thus, its level of expression may not necessarily be coordinated with the GTFs (see Discussion). 
Figure 5. Immunoprecipitation of the TFID-TFIIA complex. (A) The p37 subunit of TFIIA was visualized using TFIIA- $\alpha$ antibodies in Western blot analysis from immunoprecipitation reactions of nuclear extracts (NE) using TBP monoclonal antibodies (lane 1) or anti-TFIIA- $\alpha$ antibodies (lane 2). Immunoprecipitation of $\mathrm{p} 37$ was from a partially purified fraction of TFIIA (DEAE5PW) with TBP antibodies (lane 3) or with anti-TFIIA- $\alpha$ antibodies (lane 4). TFIIA from the DEAE-5PW protein fraction was loaded directly and visualized with TFIIA- $\alpha$ antibodies (lane 5). (B) Western blot analysis using TBP monoclonal antibodies to visualize TBP shows that anti-TFIIA- $\alpha$ antibodies do not coimmunoprecipitate TBP from a purified fraction of TFIID (DEAE-52; see Maldonado et al. 1990) (lane 1) but coimmunoprecipitate TBP in the presence of purified TFIIA (DEAE-5PW, lane 2). Immunoprecipitation reactions were performed with TBP antibodies with purified TFIIA (DEAE-

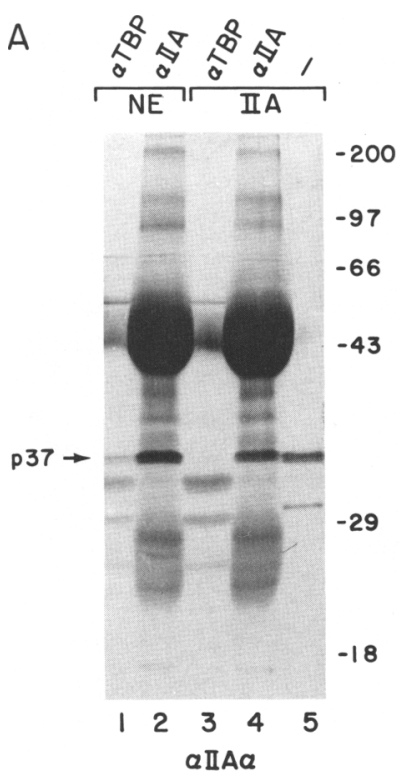

B

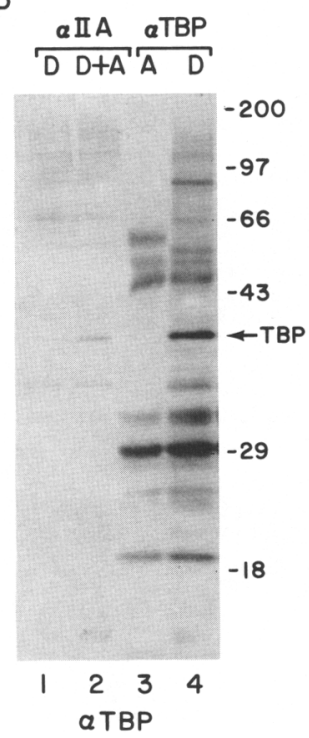

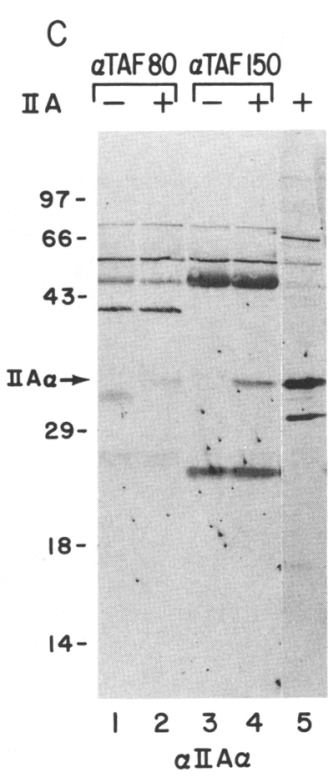

5 PW, lane 3) or purified TFIID (DEAE-52, lane 4). Molecular mass markers are indicated at right. The arrow denotes TBP. (C) Western blot analysis of the TFIIA- $\alpha$ protein coimmunoprecipitated from an affinity-purified TFIID fraction using TAF80 monoclonal antibodies in the absence (lane 1) and in the presence of TFIIA (DEAE-5PW, lane 2). The same analysis was performed using TAF150 monoclonal antibodies in the absence (lane 3) and in the presence of TFIIA (lane 4). Lane 5 represents the purified TFIIA fraction (DEAE-5PW) loaded directly and visualized using anti-TFIIA- $\alpha$ antibodies. The TFIID complex was immunopurified as described by Pugh and Tjian (1990). The complex was washed extensively with a buffer containing $1.0 \%$ NP-40, followed by a wash with PBS (see Materials and methods). The complex was then mixed with TFIIA and reimmunoprecipitated as indicated above.

An unexpected and interesting finding was made when amino acid sequences derived from the $19-\mathrm{kD}$ component of TFIIA ( $\beta$-subunit) were analyzed. Digestion of the $\beta$-subunit of TFIIA with LysC-endopeptidase resulted in the recovery of three peptides that were sequenced. Surprisingly, the sequence of each of these peptides was entirely contained in the carboxyl terminus of the cDNA clone encoding TFIIA- $\alpha$ (Fig. 1A, peptides 1-3). Thus, this result led us to estimate the mass of the recombinant protein with respect to the $\alpha$-subunit of TFIIA. The recombinant protein produced two predominant polypeptides that specifically reacted with the anti-TFIIA- $\alpha$ antibodies (Fig. 7A, lane 2): a polypeptide of $\sim 60 \mathrm{kD}$, representing the polypeptide encoded by the cDNA, and a polypeptide of $\sim 85 \mathrm{kD}$, representing a fusion of glu- tathionine $S$-transferase (GST) and the protein encoded by the cDNA (data not shown). The $\alpha$-subunit of TFIIA migrated on SDS-PAGE with a mass of $\sim 37 \mathrm{kD}$ (lane 1). This observation indicates that the isolated cDNA clone encodes a precursor of TFIIA- $\alpha$. Whether this clone also encoded the $\beta$-subunits of TFIIA, which is produced by protein processing, remains a possibility and is currently under study.

\section{Discussion}

We report the isolation of a human cDNA clone encoding the largest subunit of TFIIA. These analyses allow us to conclude that (1) the gene encoding the $\alpha$-subunit of TFIIA is complex and capable of producing three differ-
Figure 6. Northern blot analysis of RNA complementary to TFIIB and TFIIA- $\alpha$. The entire coding sequences of TFIIA- $\alpha$ and TFIIB were labeled by random priming and used in the analysis. Filters containing similar amounts of poly $(A)^{+}$RNA obtained from different human tissues was obtained from Clonetech and used as described.
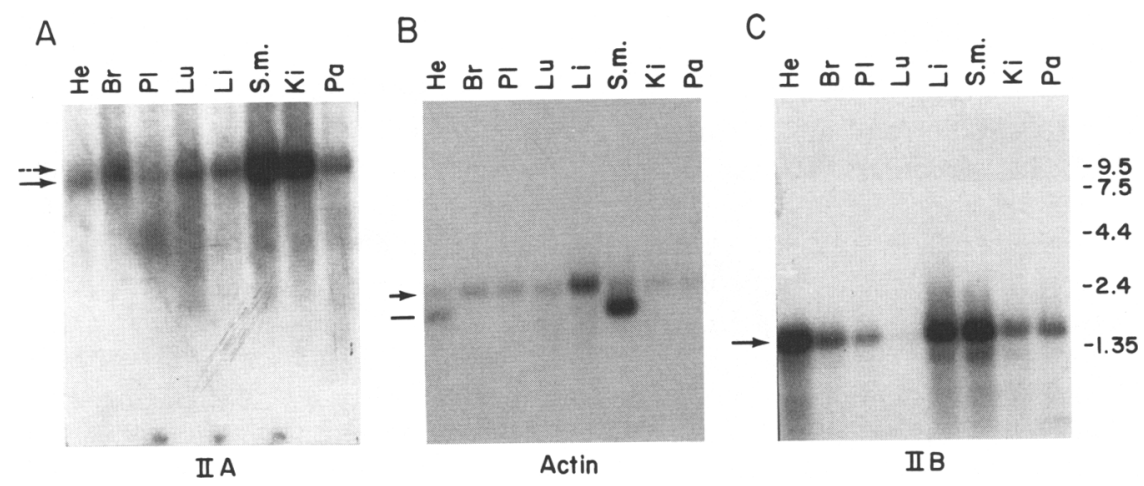


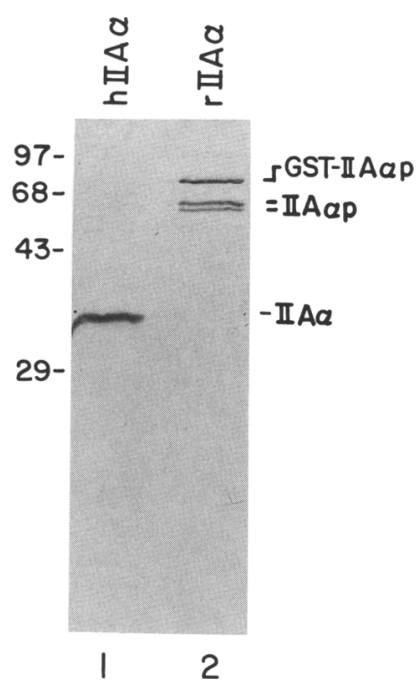

Figure 7. The TFIIA- $\alpha$ cDNA clone encodes a polypeptide larger than the $\alpha$-subunit of TFIIA. The polypeptide encoded by the longest cDNA clone was expressed as a fusion protein with GST in bacteria. Recombinant protein was purified by glutathione affinity chromatography. An aliquot of the sample $(20 \mu \mathrm{g})$ was digested with thrombin, and the recombinant protein was repurified by glutathione affinity chromatography. An aliquot of the flowthrough of the affinity column (100 ng) was analyzed by electrophoresis on a $15 \%$ polyacrylamide-SDS gel, followed by western blot using antibodies directed against the aminoterminal 50 amino acids of TFIIA- $\alpha$. (Lane 1) The reaction observed with highly purified TFIIA (see Fig. 2A). Molecular mass markers are indicated at left. The notation on the right side of the panel denotes the $\alpha$-polypeptide of TFIIA, the putative precursor of TFIIA- $\alpha$ (IIA $\alpha \mathrm{p})$, and the GST fusion protein (GSTIIA $\alpha$ p).

ent polypeptides: TFIIA- $\alpha$, an amino-terminally truncated protein $\left(\alpha^{*}\right)$, and the $\beta$-subunit of TFIIA; (2) TFIIA has no role in basal transcription but plays an important role in activation; and (3) TFIIA not only interacts with TBP but also associates with the TFIID complex in vivo.

\section{The TFIIA- $\alpha$ gene}

Two different cDNA clones differing in their $5^{\prime}$ sequences were isolated. The longer cDNA encoded the largest subunit of TFIIA as demonstrated by independent assays. We found that antibodies raised against the recombinant protein interfere with TFIIA activities. Importantly, our studies demonstrated that the recombinant polypeptide could reconstitute TFIIA activity when mixed with the two other subunits of TFIIA (Fig. 3B). The shorter cDNA clone encoded a protein lacking the first amino-terminal 39 amino acids. This protein $\left|\alpha^{*}\right|$ was not able to fully reconstitute the ability of TFIIA to interact with a TBP-DNA complex under conditions where the $\alpha$-subunit fully reconstituted TFIIA activity (in the presence of $\beta$ - and $\gamma$-subunits of TFIIA), suggesting that the amino-terminal 39 amino acids of $\alpha$ are important for TFIIA activity.
Whereas human TFIIA activity is composed of three polypeptides, the yeast TFIIA homolog is composed of two subunits, each of which is encoded by a different gene, TOA 1 and TOA 2 respectively (Ranish et al. 1992). The human $\alpha$-subunit of TFIIA shows sequence homology with TOAl, albeit the regions in common are restricted to the amino and carboxyl termini of the proteins (Fig. 1B). Most of the amino-terminal residues shared by the human and yeast factors are absent in the $\alpha^{*}$ polypeptide. Hahn and co-workers have demonstrated that the amino- and carboxy-terminal residues of the large subunit of yeast TFIIA are important for activity (S. Hahn, pers. comm.). Our results demonstrating that $\alpha^{*}$ polypeptide cannot fully reconstitute TFIIA activity are in agreement with the studies obtained with the yeast factor. The function of $\alpha^{*}$ is presently not known; however, it is important to note that we were unable to find this polypeptide in HeLa cells using Western blot analysis with antibodies directed against $\alpha$ or $\alpha^{\star}$. Thus, whether this truncated form of TFIIA- $\alpha$ exists in vivo is questionable.

In attempts to isolate the other subunits composing TFIIA, we found that the amino acid sequences derived from three peptides obtained from the $19 \cdot \mathrm{kD}$ subunit were entirely contained within the carboxyl terminus of TFIIA- $\alpha$ (Fig. 1). We believe that the $19-\mathrm{kD}$ subunit is encoded by the same gene encoding the $\alpha$-subunit of TFIIA and that either alternative splicing or protein processing is involved in its synthesis. Recently, it was discovered that the polypeptides composing the transcription factor HCF were generated by protein processing. $\mathrm{HCF}$, or host cell factor, is a multisubunit complex that links Oct-1 to the viral activator VP16 /Gerster and Roeder 1988; Kristie and Sharp 1990; Stern and Herr 1991). Wilson et al. (1993) demonstrated that a 300-kD precursor polypeptide is processed into a multitude of subunits that remain associated and constitute HCF activity. Our preliminary results, together with observations analyzing the Drosophila TFIIA, suggest that protein processing is utilized to generate the $19-\mathrm{kD} \beta$-subunit of TFIIA. Drosophila TFIIA, like its human counterpart, appears to be composed of three subunits with molecular masses of $\sim 30,20$, and $13 \mathrm{kD}$ (R. Tjian, pers. comm.). A Drosophila cDNA clone encoding a polypeptide of $\sim 48 \mathrm{kD}$ and sharing extensive homology at the amino and carboxyl termini to the yeast and human TFIIA largest subunits was isolated (R. Tjian, pers. comm.). Interestingly, the polypeptide encoded by the Drosophila cDNA clone appears to be a precursor, which is processed in vivo to generate the $30-$ and $20-\mathrm{kD}$ subunits of TFIIA (Yokomori et al., this issue). Although we cannot conclude unequivocally that the $19-\mathrm{kD}$ subunit of human TFIIA is generated by protein processing, as appears to be the case in Drosophila, it is important to note that by using the two-hybrid system in yeast (Chien et al. 1991; Zervos et al. 1993), we were able to isolate a partial cDNA clone encoding a protease that specifically interacts with the $\alpha$-subunit of human TFIIA ( $R$. Shiekhattar, F. Romero, and D. Reinberg, unpubl.). In the context of the data presented here, this finding further 
supports a model whereby the human $\beta$-subunit of TFIIA is generated by protein processing.

\section{TFIIA functions as a coactivator}

The role of TFIIA in transcription has been a subject of major controversy, as variable requirements for the factor in transcription have been reported. This controversy can now be reconciled because of two observations. First, the TFIIA protein fraction described initially was found to contain two activities, TFIIA and TFII) (Flores et al. 1992). TFII is required for basal transcription. Second, TFIIA and TFIIJ are present in the TFIID protein fraction (Flores et al. 1992). Thus, depending on the purity of the TFIID fraction used to reconstitute transcription, variable requirements for the TFIIA protein fraction can be observed. Moreover, the studies described here and elsewhere (Cortes et al. 1992) demonstrate that TFIIA has no role in basal transcription, provided that the transcription system is reconstituted with purified components. Earlier studies (Usuda et al. 1991; Cortes et al. 1992; Coulombe et al. 1992) demonstrated that TFIIA interacts with the TBP. Despite the fact that an interaction between TBP and TFIIA could be demonstrated, Cortes et al. (1992) found that transcription reactions reconstituted with TBP were unaffected by TFIIA. However, when the transcription assays were reconstituted with TFIID (in lieu of TBP), TFIIA stimulated transcription. These apparently conflicting reports were reconciled by postulating the presence of factors in the TFIID complex that negatively affected transcription (Cortes et al. 1992). Since this initial hypothesis, factors that interact with TBP and repress transcription have been isolated in human cells (Meisterernst and Roeder 1991; Meisterernst et al. 1991; Inostroza et al. 1992; Merino et al. 1993) and in yeast (Auble and Hahn 1993). Moreover, the interaction between the negative components of transcription and TBP appears to be in competition with TFIIA (Meisterernst and Roeder 1991; Meisterernst et al. 1991; Auble and Hahn 1993; Merino et al. 1993). In the studies presented here, we extended these observations and demonstrated that anti-TFIIA antibodies can block the ability of TFIIA to overcome repression, thus emphasizing the role of TFIIA in this function. The most revealing finding was the discovery that TFIIA is required for activation of transcription by Gal4-VP16 and Gal4-Pro. The antibodies raised against the largest recombinant subunit of TFIIA can block activation. Because physiological levels of activated transcription cannot yet be achieved in a system reconstituted with purified components, the activation assays were performed using nuclear extracts. Moreover, because reconstitution of transcriptional activation in vitro requires $\mathrm{Dr}_{2}$, a repressor of transcription (Merino et al. 1993; for review, see Drapkin et al. 1993), we are unable to invoke a direct effect of TFIIA in this process other than removing factors that negatively affect transcription and possess a dominant effect. However, our results demonstrating a function of TFIIA in activation of transcription, together with those that detect human (Fig. 5) and Drosophila (Yokomori et al., this issue/ TFIIA in the TFIID complex, strongly suggest a functional role for TFIIA in activation. These observations are supported further by studies demonstrating that TFIIA not only interacts with the TBP component of TFIID but also with the Drosophila TAF110 (R. Tjian, pers. comm.), a TAF important for Spl activation (Hoey et al. 1993). Thus, our studies, together with those obtained with Drosophila TFIIA, demonstrate a role of the factor in transcriptional activation. Our results are consistent with studies in yeast demonstrating that the genes encoding each of the subunits of TFIIA are essential for viability.

\section{Materials and methods}

\section{Purification of TFIIA}

TFIIA was purified from the phosphocellulose $0.1 \mathrm{M} \mathrm{KCl}$ protein fraction (Reinberg et al. 1987) as described previously by Usuda et al. (1991) and Cortes et al. (1992). Both a functional transcription assay and the ability of TFIIA to affect the binding of TBP to the TATA motif on a gel mobility shift assay were employed to isolate TFIIA. The last step of the purification involves TBP affinity chromatography. This sample was precipitated with TCA, and the precipitate was resolved by SDS-PAGE. The polypeptides composing TFIIA were directly excised from the gel or transferred to PVDF membrane. The subunits of TFIIA were digested with lysyl- or LysC-endopeptidases. Peptides were fractionated by reverse-phase HPLC and subjected to microsequencing.

The sequence of the largest subunit of TFIIA reveals the presence of seven consecutive histidine residues; thus, TFIIA was purified using nickel and TBP affinity chromatography. One hundred milliliters of the phosphocellulose $0.1 \mathrm{M} \mathrm{KCl}$ fraction $(2.8 \mathrm{mg} / \mathrm{ml})$ was dialyzed against buffer $\mathrm{C}[20 \mathrm{~mm}$ Tris $-\mathrm{HCl} / \mathrm{pH}$ $7.91,10 \%$ glycerol, $1 \mathrm{~mm}$ ethylenediamine tetraacetic acid, 0.2 mM phenylmethylsulfonyl fluoride, and $20 \mathrm{~mm} \beta$-mercaptoethanol containing $0.5 \mathrm{M} \mathrm{KCl}$ and $1 \mathrm{~mm}$ imidazole. The protein mixture was then mixed with $3 \mathrm{ml}$ of nickel-agarose that had been equilibrated with the same buffer and incubated at $4^{\circ} \mathrm{C}$ for $1 \mathrm{hr}$ with constant agitation. The nickel resin was recovered by centrifugation on a tabletop centrifuge and was washed with 10 column volumes $(30 \mathrm{ml})$ of buffer $C$ containing $0.1 \mathrm{M} \mathrm{KCl}$ and 1 $\mathrm{mM}$ imidazole. This wash was followed by a second wash in which the concentration of imidazole was increased to $5 \mathrm{~mm}$. The activity was eluted from the column with a linear gradient (10 volume) of imidazole $(5-60 \mathrm{~mm}$ ) in buffer $C$ containing $0.1 \mathrm{M}$ $\mathrm{KCl}$. The activity eluted between 20 and $30 \mathrm{~mm}$ imidazole. The protein pool $(18 \mathrm{ml}, 0.6 \mathrm{mg} / \mathrm{ml})$ was dialyzed against buffer $\mathrm{C}$ containing $0.1 \mathrm{M} \mathrm{NaCl}$ and $20 \%$ glycerol and loaded onto a 1.3-ml TBP affinity column (Cortes et al. 1992). The column was washed with $20 \mathrm{ml}$ of buffer $\mathrm{C} / 0.1 \mathrm{NaCl}$, and the activity eluted with a $4-\mathrm{ml}$ wash of buffer $\mathrm{C}$ containing $0.5 \mathrm{M} \mathrm{NaCl}$. The protein concentration of the recovered sample was $\sim 23 \mu \mathrm{g} / \mathrm{ml}$.

\section{Molecular cloning of the large subunit of TFIIA}

Treatment of the TFIIA/37-kD polypeptide with LysC-endopeptidase resulted in the recovery of four peptides (Fig. 1A, labeled $\mathrm{a}-\mathrm{d} \mid$ that were subjected to microsequencing. Treatment of the polypeptide with lysyl-endopeptidase resulted in the recovery of three peptides (Fig. 1A, e-g). A degenerate oligonucleotide deduced from the amino acid sequence derived from peptide $g$ was synthesized: 5'-CAA/GGTIATICCIACIACIGTI- 
GCIGCICCIACICCIGCICAA/GGC-3'. This oligonucleotide was used to screen a HeLa cellular cDNA library. As described in the text, two cDNA clones differing in their 5' sequences were obtained. The complete sequence of the larger cDNA clone, encoding TFIIA- $\alpha$, is shown in Figure 1A. The $5^{\prime}$-unique sequences of the shorter CDNA clone is shown in the legend to Figure 1(A).

\section{Expression of recombinant TFIIA- $\alpha$ and TFIIA- $\alpha^{*}$}

DNA fragments encoding the $\alpha$ and $\alpha^{*}$ polypeptides were obtained using PCR. The DNA fragments were inserted into the SmaI site of pGEX-2T (Pharmacia). E. coli cells were transformed, and induction was performed. The GST fusion proteins were purified by glutathione affinity chromatography according to the manufacturer's specifications. Four hundred micrograms of affinity-purified GST- $\alpha$ and GST- $\alpha^{*}$ was digested with thrombin $(1.5 \mathrm{U} / \mathrm{ml})$ and then sequentially passed through benzamidine-Sepharose and glutathione-Sepharose to remove thrombin and GST. The flowthrough fraction was used as recombinant $\alpha$ and $\alpha^{*}$. Because extensive degradation of the E. coli-expressed polypeptides was observed occasionally, the following procedure was used to isolate recombinant proteins. Proteins were expressed in E. coli, lysed, and separated immediately by preparative SDS-PAGE. The GST $\alpha$ and GST $\alpha^{*}$ polypeptides were isolated from the gel. Following renaturation, the fusion proteins were digested with thrombin. GST and thrombin were removed as described above. Renaturation of the recombinant polypeptides, as well as the other subunits of TFIIA $\{\beta$ and $\gamma \mid$, was performed as described previously (Cortes et al. 1992).

\section{Antibodies against TFIIA- $\alpha$ and TFIIA $-\alpha^{*}$}

Recombinant proteins were isolated from preparative SDSPAGE. The bands corresponding to the recombinant fusion proteins were recovered $(\sim 200 \mu \mathrm{g})$ and purified further by GST affinity chromatography. The protein sample was mixed with complete Freund's adjuvant and injected into rabbits. Fifteen days after the first injection, another injection was given in incomplete Freund's adjuvant with the protein prepared as described above. Bleeding was performed 10 days after the second injection, and serum was prepared.

\section{Transcription and DNA-binding assays}

A DNA template containing five GAL4-DNA-binding sites upstream of the TATA motif of the adenovirus major late promoter (Ad-MLP), was mixed with a second template lacking GAL4-DNA-binding sites. Transcription reactions were performed as described previously. Each reaction contained $200 \mathrm{ng}$ of each DNA template. Transcription factors and RNAPII (Lu et al. 1991) were purified as described previously: rIIB (Ha et al. 1991), rIID or TBP (as described in the figures; Maldonado et al. 1990), rIIE (Peterson et al. 1991), rIIF (L. Zawel and D. Reinberg, in prep.), rIIJ (Flores et al. 1992), and rIIH (Lu et al. 1992). The RNA products were analyzed on a polyacrylamide-urea gel. The synthetic transcriptional activators GAL4-VP16 and the DNAbinding domain of GAL4(1-94) were purified as described (Chasman et al. 1989; Baichwal and Tjian 1990). All proteins were kept in buffer $\mathrm{C}$ containing $0.1 \mathrm{M} \mathrm{KCl}$. $\mathrm{Dr}_{2}$ was purified from the phosphocellulose $1.0 \mathrm{M}$ fraction described previously (Merino et al. 1993). DNA-binding assays were performed as described by Maldonado et al. (1990).

\section{Immunoprecipitation reactions and Western blot analysis}

Antibodies against TFIIA and TBP were incubated with protein A-Sepharose (Repligen) for $30 \mathrm{~min}$ at $23^{\circ} \mathrm{C}$ followed by the ad- dition of nuclear extracts or purified fractions and then incubated for an additional $2 \mathrm{hr}$ at $4^{\circ} \mathrm{C}$ with mixing. Immunoprecipitates were washed with ice-cold lysis buffer containing $50 \mathrm{~mm}$ Tris- $\mathrm{HCl}$ buffer (pH 7.5), $50 \mathrm{~mm} \mathrm{NaF}, 100 \mu \mathrm{M} \mathrm{NaVO}, 150 \mathrm{~mm}$ $\mathrm{NaCl}, 1 \mathrm{mM}$ PMSF, and $1 \% \mathrm{NP}-40$ and one time with PBS. Samples were then eluted from the protein A-resin antibody complexes using $200 \mathrm{~mm}$ glycine- $\mathrm{HCl}(\mathrm{pH} \mathrm{2.6)}$, boiled for $5 \mathrm{~min}$ in Laemmli sample buffer, resolved by $13 \%$ SDS-polyacrylamide gel electrophoresis, and transferred to nitrocellulose membrane. The blot was blocked with $5 \%$ BSA in TBS, $0.05 \%$ Tween 20 for $2 \mathrm{hr}$, and incubated with either TFIIA- $\alpha$ or monoclonal TBP antibodies for $2 \mathrm{hr}$ at room temperature, followed by secondary antibodies conjugated to either horseradish peroxidase or alkaline phosphatase for $1 \mathrm{hr}$. Horseradish peroxidase conjugates were visualized using the chemiluminescence system (Amersham), and alkaline phosphatase-coupled material was visualized using nitro blue tetrazolium (NBT) and bromochloroindolul phosphate (BCIP).

\section{Acknowledgments}

We thank Drs. N. Hernandez for the gift of TBP monoclonal antibodies, R. Tjian for the gift of anti-human TAF80 and TAF150 antibodies, and M. Green for the gift of Gal4-Pro fusion protein. We thank Drs. R. Tiian and S. Hahn for active discussions and tje communication of results before publication. We are grateful to R. Drapkin and L. Zawel for reading the manuscript. This work was supported by grants from the National Institutes of Health (NIH) to D.R, and a grant-in-aid for Scientific Research on Priority Areas and from the Human Frontier Science Program (HFSP) research grant to H.H. F.M. was supported by a postdoctoral fellowship from the NIH. D.R. is a recipient of an American Cancer Society Faculty Research Award.

The publication costs of this article were defrayed in part by payment of page charges. This article must therefore be hereby marked "advertisement" in accordance with 18 USC section 1734 solely to indicate this fact.

\section{Note added in proof}

The sequence data for TFIIA- $\alpha$ have been submitted to the EMBL data library under accession number X75383.

\section{References}

Auble, D. and S. Hahn. 1993. An ATP-dependent inhibitor of TBP binding to DNA. Genes \& Dev. 7: 844-856.

Baichwal, V. and R. Tjian. 1990. Control of c-jun activity by interaction of a cell-specific inhibitor with regulatory domain: Differences between v- and c-jun. Cell 63: 815-825.

Buratowski, S. and H. Zhou. 1992. TFIID mutants defective for interaction with TFIIA. Science 55: 1130-1132.

Buratowski, S., S. Hahn, L. Guarente, and P. Sharp. 1989. Five intermediate complexes in transcription initiation by RNA polymerase II. Cell 56: 549-561.

Chasman, D.I., J. Leatherwood, M. Carey, M. Ptashne, and R.D. Kornberg. 1989. Activation of yeast polymerase II transcription by herpesvirus VP16 and Gal4 derivatives in vitro. Mol. Cell. Biol. 9: 4746-4749.

Chien, C.-T., P. Bartel, R. Sternglanz, and S. Fields. 1991. The two-hybrid system: A method to identify and clone genes for proteins that interact with a protein of interest. Proc. Natl. Acad. Sci. 88: 9578-9582.

Cortes, P., O. Flores, and D. Reinberg. 1992. Factors involved in specific transcription by mammalian RNA polymerase II: 
Purification and analysis of transcription factor IIA and identification of transcription factor IIJ. Mol. Cell. Biol. 12: 413421.

Coulombe, B., M. Killeen, P. Liljelund, B. Honda, H. Xiao, C.J. Ingles, and J. Greenblatt. 1992. Identification of three mammalian proteins that bind to the yeast TATA box protein TFIID. Gene Expression 2: 99-110.

Drapkin, R., A. Merino, and D. Reinberg. 1993. Regulation of RNA polymerase II transcription. Curr. Opin. Cell Biol. 5: 469-476.

Dynlacht, B.D., T. Hoey, R. and R. Tjian. 1991. Isolation of coactivators associated with the TATA-binding protein that mediate transcriptional activation. Cell 66: 563-576.

Dynlacht, B., R. Weinzierl, A. Admon, and R. Tjian. 1993. The dTAFII80 subunit of Drosophila TFIID contains beta-transducin repeats. Nature 363: 176-179.

Flanagan, J., K. Becker, D. Ennist, S. Gleason, P. Driggers, B.-Z. Levi, E. Appella, and K. Ozato. 1992. Cloning of a negative transcription factor that binds to the upstream conserved region of moloney murine leukemia virus. Mol. Cell. Biol. 12: $38-44$.

Flores, O., H. Lu, and D. Reinberg. 1992. Factors involved in specific transcription by mammalian RNA polymerase II. Identification and characterization of factor IIH. $J$. Biol. Chem. 267: 2786-2793.

Gerster, T. and R. Roeder. 1988. A herpes virus trans-activating protein interacts with transcription factor OTF-1 and other cellular proteins. Proc. Natl. Acad. Sci. 85: 6347-6351.

Goodrich, J., T. Hoey, C. Thut, A. Admon, and R. Tjian. 1993. Drosophila TAFII40 interacts with both a VP16 activation domain and the basal transcription factor TFIIB. Cell (in press).

Ha, I., W.S. Lane, and D. Reinberg. 1991. Cloning of a human gene encoding the general transcription factor IIB. Nature 352: 689-695

Ha, I., S. Roberts, E. Maldonado, X. Sun, M.R. Green, and D. Reinberg. 1993. Multiple functional domains of human transcription factor IIB: Distinct interactions with two general transcription factors and RNA polymerase II. Genes \& Dev. 7: 1021-1032.

Hariharan, N., D. Kelley, and R. Perry. 1991. $\delta$, a transcription factor that binds to downstream elements in several polymerase II promoters, is a functionally versatile zinc finger protein. Proc. Nat1. Acad. Sci. 88: 9799-9803.

He, X., R. Gerrero, D. Simmons, R. Park, C. Lin, L. Swanson, and M. Rosenfeld. 1991. Tst-1, a member of the POU domain gene family, binds the promoter of the gene encoding the cell surface adhesion molecule Po. Mol. Cell. Biol. 11: 17391744.

Hernandez, N. 1993. TBP, a universal eukaryotic transcription factor? Genes \& Dev. 7: 1291-1308.

Hisatake, K., S. Hasekawa, R. Takada, Y. Nakatani, M. Horikoshi, and R. Roeder. 1993. The p250 subunit of native TATAbinding factor TFIID is the cell-cycle regulatory protein CCG1. Nature 362: 179-181.

Hoey, T., R.O.J. Weinzierl, G. Grace, J.L. Chen, B.D. Dynlacht, and R. Tjian. 1993. Molecular cloning and functional analysis of Drosophila TAF110 reveal properties expected of activators. Cell 72: 247-260.

Hoffman, A., E. Sinn, T. Yamamoto, J. Wang, A. Roy, M. Horikoshi, and R. Roeder. 1990. Highly conserved core domain and unique $\mathrm{N}$-terminus with presumptive regulatory motifs in a human TATA factor (TFIID). Nature 346: 387-390.

Horikoshi, N., K. Maguire, A. Kralli, E. Maldonado, D. Reinberg, and R. Weinmann. 1991. Direct interaction between adenovirus E1A protein and the TATA box binding transcription factor TFIID. Proc. Natl. Acad. Sci. 88: 5124-5128.

Ingles, C.J., M. Shales, W.D. Cress, S.J. Triezenberg, and J. Greenblatt. 1991. Reduced binding of TFIID to transcriptionally compromised mutants of VP16. Nature 351: 588-590.

Inostroza, J.A., F.H. Mermelstein, I. Ha, W.S. Lane, and D. Reinberg. 1992. Drl, a TATA-binding protein-associated phosphoprotein and inhibitor of class II gene transcription. Cell 70: $477-489$.

Kao, C., P. Lieberman, M. Schmidt, Q. Zhou, R. Pei, and A. Berk. 1990. Cloning of transcriptionally active human TATA binding protein. Science 248: 1646-1650.

Kokubo, T., D.-W. Gong, S. Yamashita, M. Horikoshi, R. Roeder, and Y. Nakatani. 1993. Drosophila 230-kD TFIID subunit, a functional homolog of the human cell cycle gene product, negatively regulates DNA binding of the TATA box-binding subunit of TFIID. Genes \& Dev. 7: 1033-1046.

Kristie, T. and P. Sharp. 1990. Interactions of Oct-1 POU subdomains with specific DNA sequences and the HSV $\alpha$-transactivator protein. Genes \& Dev. 4: 2383-2396.

LaRosa, G. and L. Gudas. 1988. Early retinoic acid-induced F9 teratocarcinoma stem cell gene ERA-1: Alternate splicing creats transcripts for a homeobox-containing protein and one lacking the homeobox. Mol. Cell. Biol. 8: 3906-3917.

Lee, D.K., J. Dejong, S. Hashimoto, M. Horikoshi, and R.G. Roeder. 1992. TFIIA induces conformational changes in TFIID via interactions with the basic repeats. Mol. Cell. Biol. 12: 5189-5196

Lee, W., C. Kao, G. Bryant, X. Liu, and A. Berk. 1991. Adenovirus E1A activation domain binds the basic repeat in the TATA box transcription factor. Cell 67: 365-376.

Lewin, B. 1990. Commitment and activation at Pol II promoters: A tail of protein-protein interactions. Cell 61: 11611164.

Liberman, P. and A. Berk. 1991. The Zta trans-activator protein stablizes TFIID association with promoter DNA by direct protein-protein interaction. Genes \& Dev. 5: 2441-2454.

Lu, H., O. Flores, R. Weinmann, and D. Reinberg. 1991. The nonphosphorylated form of RNA polymerase II preferentially associates with the preinitiation complex. Proc. Natl. Acad. Sci. 88: 10004-10008.

Lu, H., L. Zawel, J.-M. Egly, and D. Reinberg. 1992. Human general transcription factor IIH phosphorylates the C-terminal domain of RNA polymerase II. Nature 358: 641-645.

Maldonado, E., I. Ha, P. Cortes, L. Weis, and D. Reinberg. 1990. Factors involved in specific transcription by mammalian RNA polymerase II: Role of transcription factors IIA, IID, and IIB during formation of a transcription-competent complex. Mol. Cell. Biol. 10: 6335-6347.

Meisterernst, M. and R.G. Roeder. 1991. Family of proteins that interact with TFIID and regulate promoter activity. Cell 67: $557-567$

Meisterernst, M., A.L. Roy, H.M. Lieu, and R.G. Roeder. 1991. Activation of class II gene transcription by regulatory factors is potentiated by a novel activity. Cell 66: 981-993.

Merino, A., K. Madden, W.S. Lane, J. Champoux, and D. Reinberg. 1993. Topoisomerase $I$ is involved in both repression and activation of transcription. Nature 365: 327-332.

Monuki, E.S., R. Kuhn, G. Weinmaster, B.D. Trapp, and G. Lemke. 1990. Expression and activity of the POU transcription factor SCIP. Science 249: 1300-1303.

Park, K. and M. Anchison. 1991. Isolation of a candidate repressor/activator, EF-El (YY-1, $\delta)$, that binds to the immunoglobulin $\kappa 3$ ' enhancer and the immunoglobulin heavy-chain $\mu E 1$ site. Proc. Natl. Acad. Sci. 88: 9804-9808.

Peterson, M.G., N. Tanase, B.F. Pugh, and R. Tjian. 1990. Functional domains and upstream activation properties of cloned 
human TATA binding protein. Science 248: 1625-1630.

Peterson, M.G., I. Inostroza, M.E. Maxon, O. Flores, A. Admon, and D. Reinberg. 1991. Structure and functional properties of human general transcription factor IIE. Nature 354: 369373.

Pugh, B.F. and R. Tjian. 1990. Mechanism of transcriptional activation by SP1: Evidence for coactivators. Cell 61: 11871197.

Ranish, J. and S. Hahn. 1992. The yeast transcription factor TFIIA is composed of two polypeptide subunits. /. Biol. Chem. 166: 19320-19327.

Ranish, J., W. Lane, and S. Hahn. 1992. Isolation of two genes that encode subunits of the yeast transcription factor IIA. Science 255: 1130-1132.

Reinberg, D., M. Horikoshi, and R.G. Roeder. 1987. Factors involved in specific transcription by mammalian RNA polymerase II. Functional analysis of initiation factors IIA and IID and identification of a new factor operating at sequences downstream of the initiation site. J. Biol. Chem. 262: 33223330.

Ruppert, S., E.D. Wang, and R. Tjian. 1993. Cloning and expression of human TAFII250: A TBP-associated factor implicated in cell cycle regulation. Nature 362: 175-179.

Shi, Y., L.S. Chang, and T. Shenk. 1991. Transcription repression by YY1, a human GLI-Kruppel-related protein, and relief of repression by adenovirus ElA protein. Cell 67: 377388.

Stern, S. and W. Herr. 1991. The herpes simplex virus transactivator VP16 recognizes the Oct-1 homeo domain: Evidence for a homeo domain recognition subdomain. Genes \& Dev. 5: 2555-2566.

Stringer, K.F., C.J. Ingles, and J. Greenblatt. 1990. Direct and selective binding of an acidic activation domain to the TATA-box factor TFIID. Nature 345: 783-786.

Tanese, N., B.F. Pugh, and R. Tjian. 1991. Coactivators for a proline-rich activator purified from the multisubunit human TFIID. Genes \& Dev. 5: 2212-2224.

Usheva, A., E. Maldonado, A. Goldring, H. Lu, C. Houbavi, D. Reinberg, and Y. Aloni. 1992. Specific interaction between the nonphosphorylated form of RNA polymerase II and the TATA-binding protein. Cell 69: 871-881.

Usuda, Y., A. Kubota, A. Berk, and H. Handa. 1991. Affinity purification of transcription factor IIA from Hela cell nuclear extracts. EMBO /. 10: 2305-2310.

Weinzierl, R.O.J., B.D. Dynlacht, and R. Tjian. 1993. The largest subunit of Drosophila TFIID directs assembly of a complex containing TBP and coactivators. Cell 362: 511-515

Wilson, A., K. LaMarco, M. Peterson, and W. Herr. 1993. The VP16 accessory protein HCF is a family of polypeptides processed from a large precursor protein. Cell 74: 115-125.

Zawel, L. and D. Reinberg. 1992. Advances in RNA polymerase II transcription. Curr. Opin. Cell Biol. 4: 488-495.

-1993. Initiation of transcription by RNA polymerase II: a multi-step process. Prog. Nucleic Acid Res. Mol. Biol. 44: 67-108.

Zervos, A., J. Gyuris, and R. Brent. 1993. Mxil, a protein that specifically interacts with Max to bind Myc-Max recognition sites. Cell 72: 223-232.

Zhou, Q., P.M. Lieberman, T.G. Boeyer, and A.J. Berk. 1992. Holo-TFIID supports transcriptional stimulation by diverse activators and from TATA-less promoters. Genes \& Dev. 6: 1964-1974. 


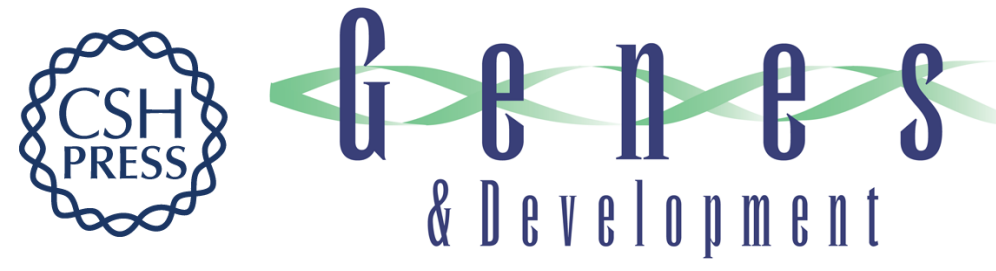

\section{Isolation of a cDNA encoding the largest subunit of TFIIA reveals functions important for activated transcription.}

$\mathrm{D} \mathrm{Ma}, \mathrm{H}$ Watanabe, $\mathrm{F}$ Mermelstein, et al.

Genes Dev. 1993, 7:

Access the most recent version at doi:10.1101/gad.7.11.2246

References This article cites 60 articles, 28 of which can be accessed free at:

http://genesdev.cshlp.org/content/7/11/2246.full.html\#ref-list-1

License

Email Alerting

Service right corner of the article or click here.

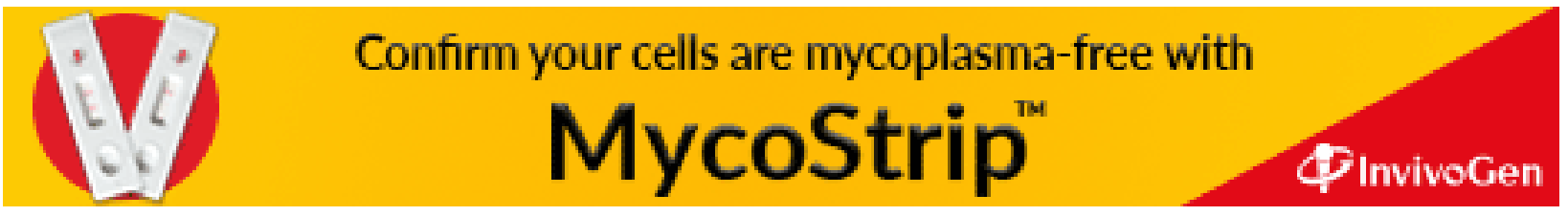

